\title{
Nitric Oxide Synthase-3 Overexpression Causes Apoptosis and Impairs Neuronal Mitochondrial Function: Relevance to Alzheimer's-Type Neurodegeneration
}

\author{
Suzanne M. de la Monte, Jean-Daniel Chiche, Annette von dem Bussche, \\ Sohini Sanyal, Stephanie A. Lahousse, Stephan P. Janssens, and Kenneth D. Bloch \\ Departments of Medicine and Pathology, Rhode Island Hospital and Brown Medical School, Providence, Rhode \\ Island (SMdIM, AvdB, SS, SAL); the Cardiovascular Research Center (JDC, KDB), Massachusetts General Hospital, \\ Harvard Medical School, Boston, Massachusetts; and the Center for Transgene Technology and Gene Therapy \\ (SPJ), Flanders Interuniversity Institute for Biotechnology, and the Cardiac Unit, University Hospital Gasthuisberg \\ University of Leuven, Leuven, Belgium
}

SUMMARY: Dementia in Alzheimer's disease $(A D)$ is correlated with cell loss that is mediated by apoptosis, mitochondrial (Mt) dysfunction, and possibly necrosis. Previous studies demonstrated increased expression of the nitric oxide synthase 3 (NOS3) gene in degenerating neurons of AD brains. For investigating the role of NOS3 overexpression as a mediator of neuronal loss, human PNET2 central nervous system-derived neuronal cells were infected with recombinant adenovirus vectors that expressed either human NOS3 or green fluorescent protein cDNA under the control of a CMV promoter. NOS3 overexpression resulted in apoptosis accompanied by increased levels of p53, p21/Waf1, Bax, and CD95. In addition, NOS3 overexpression impaired neuronal Mt function as demonstrated by the reduced levels of 3-[4,5-dimethylthiazol-2-yl]-2,5-diphenyltetrazolium bromide and nicotinamide adenine dinucleotide (reduced form)-tetrazolium reductase activities and MitoTracker Red fluorescence. These adverse effects of NOS3 were associated with increased cellular levels of reactive oxygen species and impaired membrane integrity and were not produced in cells that were transfected with a cDNA encoding catalytically inactive NOS3. Importantly, modest elevations in NOS3 expression, achieved by infection with low multiplicities of adenovirus-NOS3 infection, did not cause apoptosis but rendered the cells more sensitive to oxidative injury by $\mathrm{H}_{2} \mathrm{O}_{2}$ or diethyldithiocarbamate. In contrast, treatment with NO donors did not enhance neuronal sensitivity to oxidative injury. These results suggest that NOS3-induced neuronal death is mediated by Mt dysfunction, oxidative injury, and impaired membrane integrity, rather than by NO production, and that neuroprotection from these adverse effects of NOS3 may be achieved by modulating intracellular levels of oxidative stress. (Lab Invest 2003, 83:287-298).

$N$ itric oxide (NO) is a free radical gas that functions as a diffusable neurotransmitter and interand intracellular signaling molecule in the brain (Schmidt and Walter, 1994). At low (nM) concentrations, NO reversibly inhibits cytochrome oxidase in competition with oxygen and may have an important role in the physiological regulation of cellular energy metabolism. At higher concentrations, other respiratory chain complexes are inhibited by nitrosylation of critical tyrosine residues or oxidation of protein thiols and removal of iron from the iron-sulfur centers. Very

DOI: 10.1097/01.LAB.0000056995.07053.C0

Received October 30, 2002.

This work was supported by Grants AA-02666 and AA-10102 from the National Institutes of Health.

Address reprint requests to: Dr. S. M. de la Monte, Rhode Island Hospital, Brown Medical School, 55 Claverick Street, Room 419, Providence, RI 02903. E-mail: Suzanne_DeLaMonte_MD@Brown.edu or delamonte@hotmail.com high concentrations of $\mathrm{NO}$ promote the generation of peroxynitrite anion (ONOO-), a reaction product of superoxide plus NO, that causes irreversible inhibition of mitochondrial (Mt) respiration and damage to various Mt components via oxidizing reactions. Therefore, $\mathrm{NO}$ and its derivative peroxynitrite can inhibit Mt respiration by distinct mechanisms. In addition to direct effects of NO on cell function, many NOassociated physiological actions are mediated through increased cGMP synthesis by soluble guanylate cyclase, leading to activation of signaling cascades that involve cGMP-dependent protein kinase (Koch et al, 1994; Lincoln et al, 1997).

NO synthases (NOSs) generate NO through oxidation of a guanidino nitrogen of L-arginine. NOS1 and NOS3, initially identified in neurons and endothelial cells, respectively, are stimulated to synthesize NO by calcium/calmodulin signaling (Klatt et al, 1992; Lincoln et al, 1997). Expression of the NOS2 isoform has been detected in a number of cell types and typically is induced by lipopolysaccharide or proinflammatory cy- 
tokine stimulation (Boje and Arora, 1992; Koprowski et al, 1993; Merrill et al, 1993). In addition, the existence of a fourth NOS isoform, mitochondrial NOS (MtNOS), its $\mathrm{Ca}^{2+}$ dependence, and relevance for Mt bioenergetics were reported (Ghafourifar and Richter, 1997; Ghafourifar et al, 1999; Giulivi et al, 1998)

With disease processes such as inflammation, infection, ischemia, excitotoxic injury, or neurodegeneration, the expression of one or more NOS isoforms may be increased. Elevated levels of NOS gene expression and NO synthesis can be either detrimental or essential to cell viability and function. For example, experimental treatment of cultured neurons with $\mathrm{NO}$ donors can cause growth cone collapse (Hess et al, 1994), and in vivo, high levels of NOS expression inhibit postinjury neuronal regeneration (Mesenge et al, 1996). These adverse effects of NO can be blocked by (a) inhibiting NOS enzyme activity or gene expression (Klatt et al, 1993; Mesenge et al, 1996; Nishikawa et al, 1993), (b) enhancing superoxide dismutase activity (Satou et al, 1995), (c) treating cells with free radical/peroxynitrite scavengers (Lincoln et al, 1997), (d) providing suitable growth factors after injury (Bredt and Snyder, 1994; Klatt et al, 1992), (e) repleting co-factors that favor NO signaling rather than free radical generation, or ( $f$ ) genetically depleting NOS genes (Boje and Arora, 1992; Dinerman et al, 1994). However, in some neurons, NO plays a key role in synaptic plasticity, long-term potentiation (O'Dell et al, 1994), neurite outgrowth (Bredt and Snyder, 1994; Dinerman et al, 1994), and basal functions (Ghafourifar and Richter, 1997; Klatt et al, 1993), indicating that abolishment of NOS gene expression or NOS enzyme activity, even in disease states, would not benefit all neurons and most likely would have harmful effects in the brain.

Dementia in Alzheimer's disease (AD) is correlated with cell loss and synaptic disconnection (Esiri and Morris, 1997) mediated by apoptosis, increased Mt DNA damage, Mt dysfunction, and constitutive activation of proapoptotic mechanisms (Cotman and Su, 1996; de la Monte et al, 2000d; de la Monte et al, 1998; de la Monte et al, 1997; Kitamura et al, 1998; MacGibbon et al, 1997; Perry and Nunomura, 1998; Stadelmann et al, 1998; Su et al, 1997; Su et al, 1994; Tortosa et al, 1998). Previous studies linked $A D$ neurodegeneration to elevated levels of NOS2 and NOS3 expression in degenerating cortical neurons (de la Monte and Bloch, 1997; de la Monte et al, 2000c; Sohn et al, 1999; Vodovotz et al, 1996). The high levels of NOS2 observed in neurons with neurofibrillary tangles suggest a role for proinflammatory cytokine activation in relation to the neuronal loss that occurs in AD (Vodovotz et al, 1996). However, the more abundant and widely distributed abnormalities in NOS3 expression, combined with its early onset in relation to the time course of cognitive impairment (de la Monte and Bloch, 1997; de la Monte et al, 2000c; Sohn et al, 1999), suggest that NOS3 has a pivotal role in AD neurodegeneration. The mechanisms by which NOS3 overexpression contribute to neuronal loss in $A D$ are not known, because it is not known whether the high-level NO production or the secondary generation of reactive oxygen species, including $\mathrm{O}_{2}^{-}$, is responsible for the neuronal apoptosis and impaired Mt function. Our hypothe- sis is that chronic oxidative stress mediated by aberrant expression of NOS3 establishes a downward spiral of impaired Mt function, leading to further oxidative stress, free radical injury, impaired membrane integrity, and finally cell death. The present work investigates this hypothesis using an in vitro model of NOS3 overexpression in human central nervous system (CNS)-derived neuronal cells.

\section{Results}

\section{Overexpression of NOS3 Causes Neuronal Apoptosis}

PNET2 human CNS-derived neuronal cells (The et al, 1993; Xu et al, 1995) were used to generate a model of NOS3 overexpression because the endogenous levels of NOS3 are low and similar to the normal adult brain (de la Monte and Bloch, 1997). The cells were infected with recombinant adenovirus (Adv) that expressed complementary DNA (cDNA) encoding NOS3 or green fluorescent protein (GFP) under the control of a CMV promoter (Janssens et al, 1996; Janssens et al, 1992). Infection with Adv-NOS3 resulted in increased expression of NOS3 protein as demonstrated using the microtiter immunocytochemical enzyme-linked immunosorbent assay (MICE) (Fig. 1A). PNET2 cells that were infected with Adv-GFP had low levels of NOS3 and high levels of green fluorescence (Ex 485/Em 530) (Fig. 1B). With increasing multiplicity of infectious plaque forming units (MOI) between 10 and 100, the levels of NOS3 immunoreactivity or GFP fluorescence also increased. With an $\mathrm{MOI}$ of 50 , all cells exhibited GFP fluorescence or NOS3 expression, and further increases in GFP fluorescence or NOS3 immunoreactivity with $\mathrm{MOI}$ were due to uniformly higher cellular levels of gene expression.

Cultures infected with $30 \mathrm{MOI}$ or less of Adv-NOS3 remained viable throughout the 72 hours of study (data not shown). In contrast, cultures infected with 50 $\mathrm{MOI}$ or more of Adv-NOS3 exhibited progressive cell loss between 24 and 72 hours after inoculation, whereas cultures inoculated with the same amounts of Adv-GFP manifested progressive increases in cell density, reflecting continued net growth (Fig. 2A). For determining whether the NOS3-induced cell loss was mediated by apoptosis, the cells were analyzed using DNA fragmentation assays and H33258 staining. Quantification of the end-labeled DNA samples by scintillation counting demonstrated significantly higher levels of $\left[\alpha^{32} \mathrm{P}\right] \mathrm{dCTP}$ incorporation in genomic (Gn) DNA isolated from cells infected with Adv-NOS3 than in Gn DNA isolated from Adv-GFP-infected control cultures (Fig. 2B). The Adv-NOS3-infected cultures exhibited progressively increased DNA fragmentation with increasing $\mathrm{MOI}$ between 20 and 100, whereas the Adv-GFP-infected cells manifested minimal evidence of Gn DNA fragmentation under the same experimental conditions. In situ Hoechst H33258 staining of the cells revealed increased nuclear fragmentation and condensation in the AdvNOS3-infected cultures relative to the Adv-GFP-infected cultures, which exhibited uniform diffuse 
A

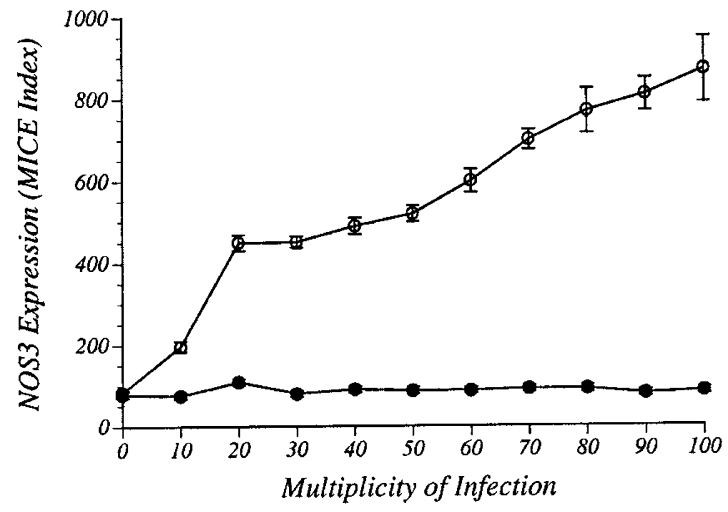

B

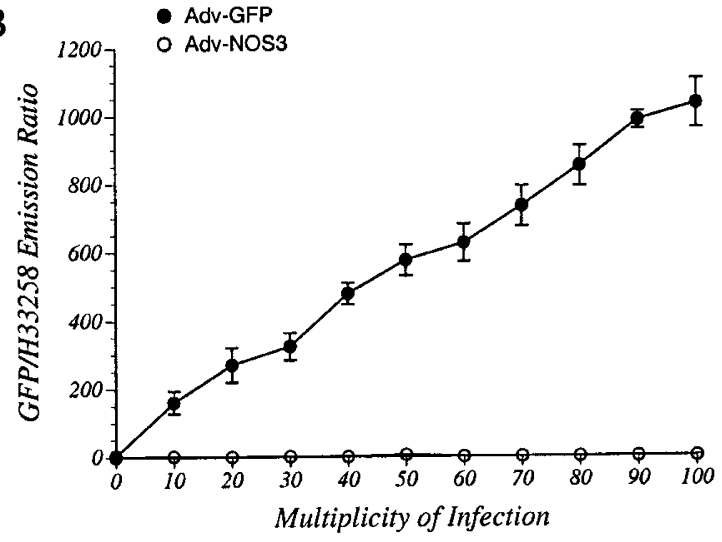

Figure 1.

Increased nitric oxide synthase 3 (NOS3; A) or green fluorescent protein (GFP; B) expression in PNET2 cells infected with adenovirus (Adv)-NOS3 or Adv-GFP. Cells grown in 96-well plates and infected with 10 to 100 multiplicity of infectious plaque forming units (MOI) of Adv-NOS3 or Adv-GFP were analyzed for NOS3 expression (A) or GFP fluorescence (B) 48 hours after inoculation. NOS3 expression was measured using the microtiter immunocytochemical enzyme-linked immunosorbent assay (MICE) assay in which the levels of immunoreactivity were corrected for cell density (see Methods). Absorbances were measured in a Spectracount microplate reader. B, GFP fluorescence was measured in a Fluorocount microplate reader (Ex 485: Em 530), after which the cells were labeled with $\mathrm{H} 33258$ and read again in the Fluorocount (Ex 360: Em 460) to determine cell density. The graph in B depicts the ratio of GFP/H33258. Values in both graphs represent the mean \pm SD of absorbance or fluorescence measured in eight replicate culture wells.

nuclear labeling (Fig. 3). With increasing MOI of AdvNOS3, the density of apoptotic bodies also increased, corresponding with the end-labeling assay results. Finally, apoptosis-associated DNA laddering was observed in Adv-NOS3-infected and not Adv-GFP-infected cells (Fig. 3D).

\section{Activation of Proapoptosis Mechanisms by NOS3 Overexpression}

Neuronal loss in $A D$ is associated with increased expression of proapoptosis genes, including, p53, CD95, and Bax (de la Monte et al, 1998; de la Monte et al, 1997; Su et al, 1997), and aberrant NOS3 expression in $A D$ is localized to brain regions that have increased levels of p53 and CD95 expression (Sohn et
A
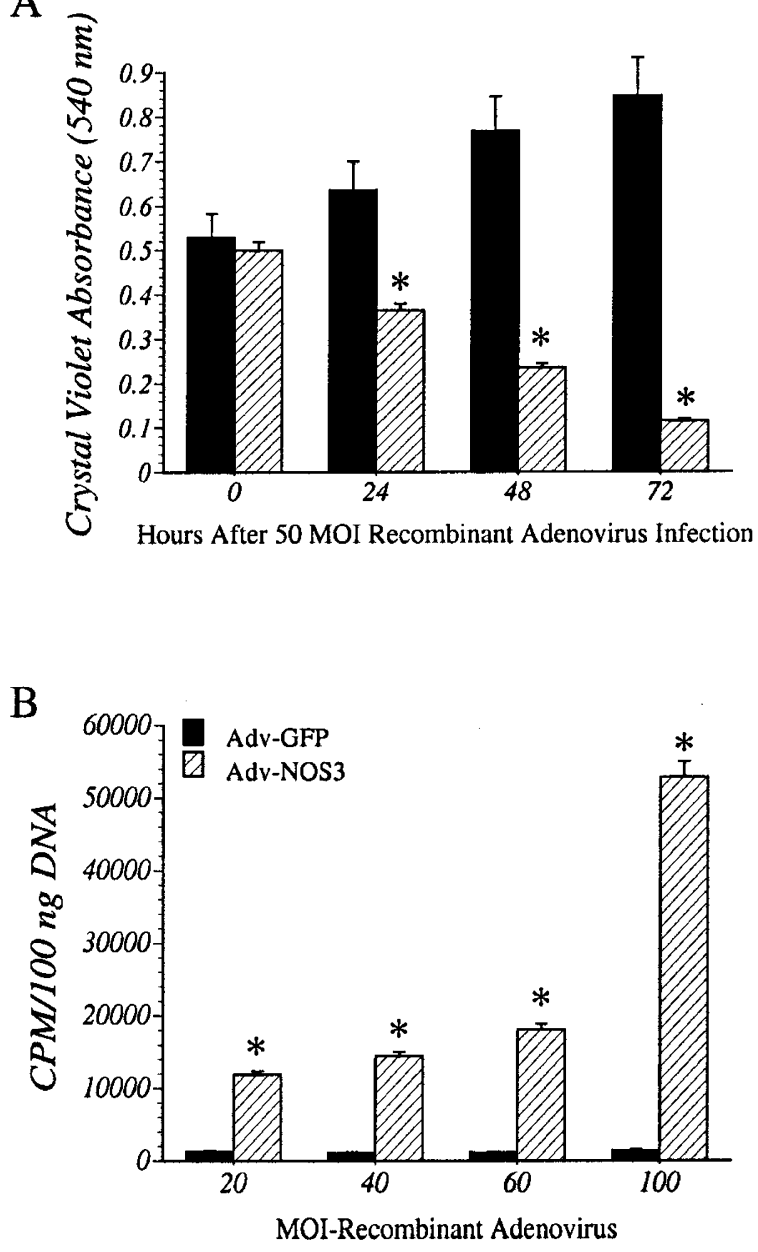

Figure 2.

Reduced viability (A) and increased genomic (Gn) DNA damage (B) with NOS3 overexpression in PNET2 neuronal cells. A, Cells that were seeded in 96-well plates $(105 /$ well) were infected with $50 \mathrm{MOI}$ of Adv-NOS3 or Adv-GFP. Viability was measured $0,24,48$, or 72 hours later using the crystal violet assay. Absorbance values are linearly correlated with cell density between $10^{4}$ and 5 $\times 10^{5}$ cells per well (data not shown). B, Gn DNA was isolated, and DNA fragmentation and nicking were assessed by $3^{\prime}$ end-labeling in primer-free assays (see Methods). The levels of $\left[\alpha^{32} \mathrm{P}\right] \mathrm{dCTP}$ incorporated into high molecular weight DNA were measured in a scintillation counter. The levels of $\left[\alpha^{32} \mathrm{P}\right] \mathrm{dCTP}$ incorporation in uninfected cultures were the same as in the Adv-GFP-infected cultures (data not shown). The graph in A depicts the mean \pm SD of results obtained in 12 replicate culture wells. The DNA fragmentation assays were performed using Gn DNA isolated from six replicate cultures. Between-group comparisons were made using ANOVA with Fisher least significant difference (LSD) post hoc tests for significance $\left({ }^{\star} p<0.001\right)$.

al, 1999). For determining whether NOS3-induced neuronal cell death was mediated by similar proapoptosis mechanisms, p53, CD95, and Bax expression were examined by Western blot analysis or the MICE. In addition, p21/Waf1 expression was measured because p53-induced apoptosis can be mediated through p21/Waf1 (el-Deiry, 1997). With increasing $\mathrm{MOI}$, the Adv-NOS3-infected cells exhibited progressively increased levels of NOS3, p53, and p21/Waf1 relative to the Adv-GFP-infected control cells, as demonstrated by Western blot analysis (Fig. 4A). In contrast, similar levels of Mt structural protein expression were observed in both groups, and the levels did 

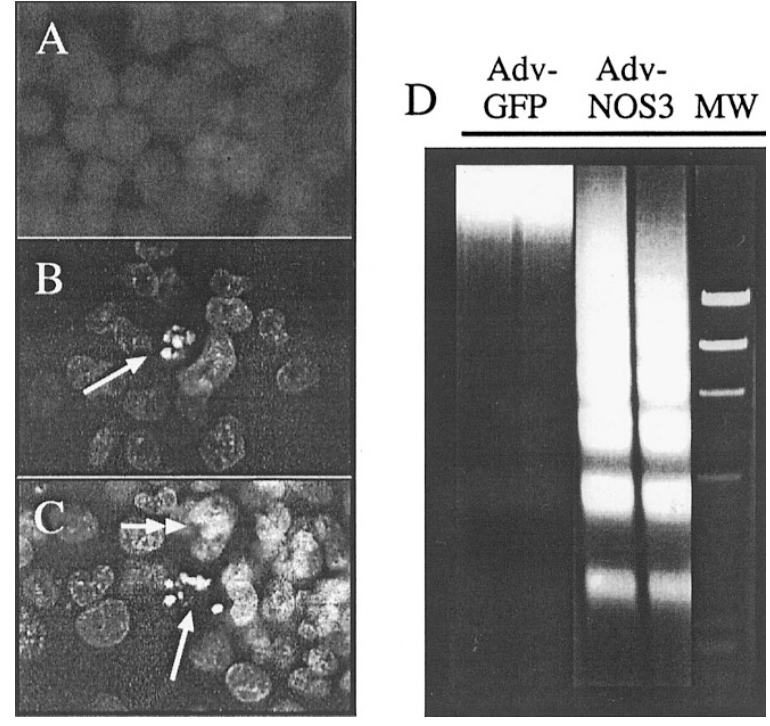

Figure 3.

Increased apoptosis in cultures that were infected with Adv-NOS3. Cells that were seeded in 96-well plates (105/well) were infected with Adv-GFP (A) or Adv-NOS3 (B and C). After 24 hours, the cells were fixed, permeabilized, and then stained with Hoechst H33258. Fluorescence microscopy revealed uniform labeling of nuclei in control cultures that were infected with $50 \mathrm{MOI}$ of Adv-GFP (A), and increased nuclear fragmentation (B and $\mathrm{C}$, arrows) and condensation (C, double-headed arrow) in cultures that were infected with $20 \mathrm{MOI}$ (B) or 50 MOI of Adv-NOS3 (B and C, arrows). Note the increased density of cells with nuclear abnormalities with increased MOI of Adv-NOS3. D, Gn DNA isolated from cells that were infected with $50 \mathrm{MOI}$ of Adv-NOS3 exhibited fragmentation laddering, whereas Gn DNA from Adv-GFP-infected cultures (50 MOI) remained intact as indicated by the high molecular weight profiles (MW $=\lambda$ Phage Hind III cut DNA).

not vary with $\mathrm{MOI}$. For demonstrating proapoptosis gene activation using the MICE, PNET2 cells were infected with $50 \mathrm{MOI}$ of Adv-NOS3 or Adv-GFP. Twenty-four hours after infection, the cells that were infected with Adv-NOS3 exhibited significantly increased levels of NOS3, Bax, p53, and CD95 relative to the Adv-GFP-infected cultures (Fig. 4B). In contrast, the levels of Mt protein were similar for the two groups, corresponding with results obtained by Western blot analysis.

\section{Impaired Mt Function with NOS3 Overexpression}

Mt function was assessed using the 3-[4,5dimethylthiazol-2-yl]-2,5-diphenyltetrazolium bromide (MTT), nicotinamide adenine dinucleotide (reduced form)-tetrazolium reductase (NADH-TR), and MitoTracker fluorescence assays. Overexpression of NOS3 after infection with $50 \mathrm{MOI}$ of Adv-NOS3 resulted in significantly reduced levels of MTT (Fig. 5A) and NADH-TR (Fig. 5B) activities and MitoTracker Red fluorescence (Fig. 5C) after 24 hours. In contrast, MitoTracker Green fluorescence, an index of Mt mass, was unaffected by NOS3 overexpression (Fig. 5D), corresponding with the similar levels of Mt structural protein expression detected by Western blot analysis and the MICE, as shown in Figure 5.
A $\underline{\operatorname{NOS3}}$

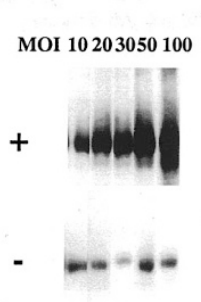

p53

MOI $10 \quad 20 \quad 30 \quad 50100$

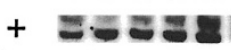

p21/Waf1

$\underline{\text { MT }}$

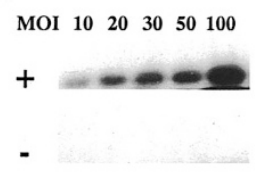

MOI $\begin{array}{llllll}10 & 20 & 30 & 50 & 100\end{array}$

$+$

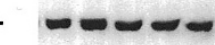

$-\quad-\infty-\infty$

B

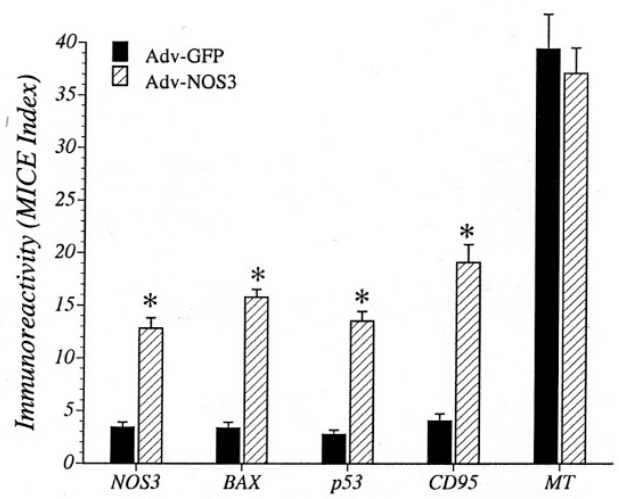

Figure 4.

NOS3-induced expression of proapoptosis genes. A, Cells grown in $100 \mathrm{~cm}^{2}$ dishes were infected with 10 to $100 \mathrm{MOI}$ of Adv-NOS3 (+) or Adv-GFP (-). The cells were harvested 24 hours after infection, and the lysates were subjected to Western blot analysis using $60-\mu \mathrm{g}$ protein samples. The blots were probed with monoclonal antibodies to NOS3, p53, p21/Waf1, or mitochondrial structural protein (MT). Immunoreactivity was revealed with horseradish peroxidase-conjugated secondary antibody, ECL reagents, and film autoradiography. B, Increased levels of NOS3, Bax, p53, and CD95, but not MT protein, in cells that were infected with Adv-NOS3. Cells were seeded into 96-well plates and infected with $50 \mathrm{MOI}$ of Adv-NOS3 or Adv-GFP. Immunoreactivity was measured using the MICE. The graphed values depict the mean \pm SD of results. Intergroup comparisons were made using ANOVA with Fisher LSD post hoc tests for significance $\left({ }^{\star} p<0.001\right)$.

\section{NOS3 Induced Oxidative Stress}

To determine whether the adverse effects of increased NOS3 expression were mediated by oxidative stress and free radical injury, we measured the levels of $\mathrm{H}_{2} \mathrm{O}_{2}$ and free radicals generated in cultures infected with $50 \mathrm{MOI}$ of Adv-NOS3 or Adv-GFP for 24 hours. In addition, nitrite production was measured using the Griess reagent assay (Molecular Probes, Eugene, Oregon). Oxidative injury and hydrogen peroxide production were measured by dihydrorosamine-6G (DHR) and Amplex Red fluorescence, respectively. DHR is a Leuco dye that passively diffuses across cell membranes and is rendered fluorescent upon reaction with hydrogen peroxide in the presence of cytochrome $\mathrm{c}$, peroxidase, or $\mathrm{Fe}^{2+}$. Therefore, DHR fluorescence indirectly reflects the production of reactive oxygen species. Amplex Red (10acetyl-3-,7-dihydrophenoxazine) is used to quantify $\mathrm{H}_{2} \mathrm{O}_{2}$ production, as the reagent is rendered fluorescent upon interaction with $\mathrm{H}_{2} \mathrm{O}_{2}$ in the presence of peroxi- 

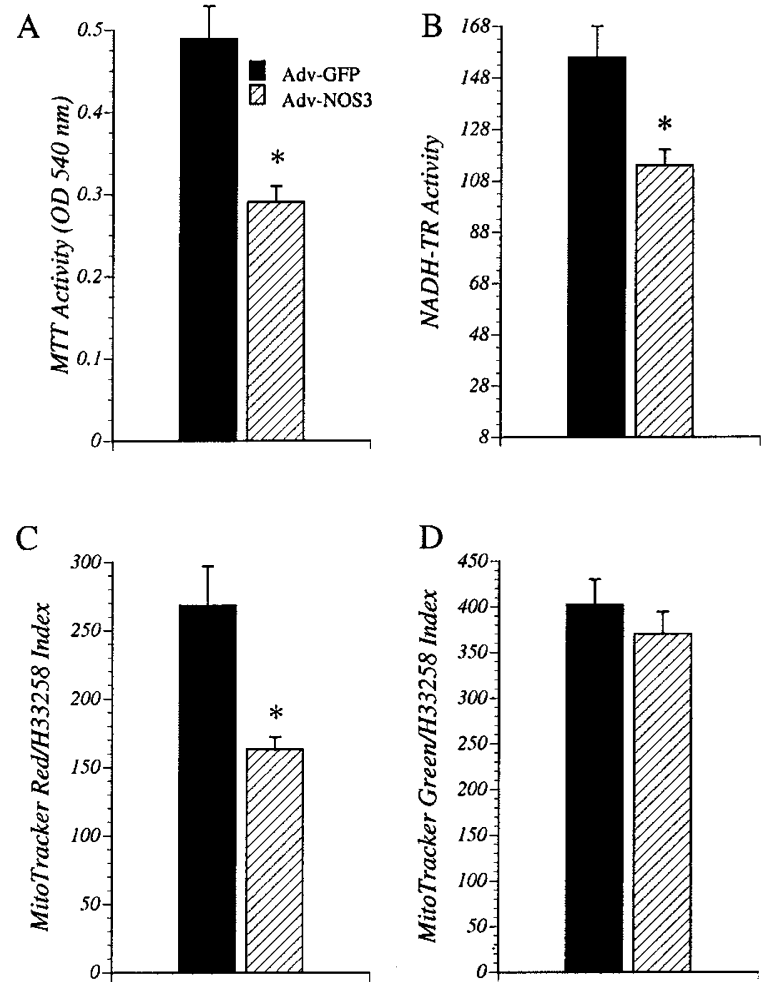

Figure 5.

Impaired mitochondrial (Mt) function associated with NOS3 overexpression. Cells that were seeded in 96 -well plates $\left(10^{5} /\right.$ well) were infected with $50 \mathrm{MOI}$ of Adv-NOS3 or Adv-GFP. After 24 hours, the cells were either analyzed for Mt function using the 3-[4,5-dimethylthiazol-2-yl]-2,5-diphenyltetrazolium bromide (MTT; A) or nicotinamide adenine dinucleotide (reduced form)tetrazolium reductase (NADH-TR) (B) assay, or they were labeled with MitoTracker Red (C) or MitoTracker Green (D), which are mitochondriaspecific fluorescent dyes that measure Mt function and Mt mass, respectively. Fluorescence intensity was measured in a Fluorocount. Subsequently, the cells were fixed and labeled with $\mathrm{H} 33258$ to assess cell density. The ratios of MitoTracker/H33258 fluorescence were calculated for each well. The MTT and NADH-TR enzyme assay results were colorimetric and measured in a Spectracount plate reader. The graphed values depict the mean \pm SD of results. Between-group comparisons were made using Student $t$ tests $\left({ }^{\star} p<0.001\right)$.

dase. Cells that were infected with Adv-NOS3 exhibited increased nitrite production and strikingly increased levels of both DHR and Amplex Red $\mathrm{H}_{2} \mathrm{O}_{2}$ fluorescence relative to Adv-GFP-infected control cultures (Fig. 6, A to D).

\section{NOS-Associated Impairment of Membrane Integrity}

Reduced energy production arising from impaired Mt function can compromise membrane integrity, resulting in increased calcium influx and further activation of cytotoxic mechanisms. The potential role of increased membrane permeability as a mediator of cell death with NOS3 overexpression was examined by assessing Calcein AM, propidium iodide, and SYTOX Green fluorescence labeling. Calcein AM is a polar dye that is rendered fluorescent by acid hydrolysis and retained in cells that have good membrane integrity. Propidium iodide and SYTOX Green nonspecifically label nucleic acids in cells with impaired membrane integrity. Cells that were infected with $50 \mathrm{MOI}$ of Adv-NOS3 had significantly reduced levels of Calcein AM retention and increased levels of SYTOX Green and propidium iodide labeling relative to the Adv-GFP-infected control group after 24 hours (Fig. 6, D to F).

\section{Control Studies to Validate Specificity of Results}

For further demonstrating specificity of neuronal responses to NOS3 and exclude effects of the Adv vector, neuronal cells were transiently transfected with human cDNAs encoding either wild-type (wt) NOS3 or NOS3 mutated in the catalytic domain (mut) as previously described (Chen et al, 1998). Parallel cultures were transfected with nonrecombinant plasmid DNA as a negative control. Experiments were performed with cells seeded into 96 -well plates at a density of $10^{4}$ viable cells/well. Cells that were transfected with different plasmids were seeded in adjacent wells on the same plates to enable intergroup comparisons. Measurements of viability, Mt function, oxidative stress, membrane permeability, and NOS3 and CD95 expression were performed 48 hours after transfection to coincide with the period of peak-level transgene expression.

Using the MICE, we demonstrated that cells that were transfected with either wt-NOS3 or mut-NOS3 had similarly elevated levels of NOS3 immunoreactivity compared with cells that were transfected with control plasmid (Fig. 7A). This result was expected because the mutations created in the mut-NOS3 construct did not abolish the binding site of the NOS3 antibody. In contrast, cells that were transfected with wt-NOS3 exhibited significantly reduced levels of viability (measured using the Crystal violet assay) and Mt function (measured using the MTT assay and MitoTracker fluorescence) relative to control cells, whereas the cells that were transfected with mut-NOS3 did not manifest impairments in either viability or Mt function (Fig. 7, B to D). In addition, cells that were transfected with wt-NOS3 had significantly increased levels of CD95 expression, DHR/H33258 (oxidative stress), and $\mathrm{PI} / \mathrm{H} 33258$ (membrane permeability) relative to control transfected cells. Transfection with the catalytically inactive mut-NOS3 had no significant effect on CD95 expression, DHR fluorescence, or PI labeling in PNET2 neuronal cells (Fig. 7, E to G). These results demonstrate that the adverse effects of NOS3 overexpression on neuronal viability, Mt function, membrane integrity, and oxidative stress require the NOS3 enzyme to be catalytically active.

\section{Potential Roles of Oxidative Stress and Mt Permeability Transition in NOS3-Mediated Death and Impaired Mt Function in Neuronal Cells}

For determining the relative roles of NO production, oxidative injury, Mt permeability transition, and mediators of neuronal death associated with NOS3 overexpression, cultures were infected with $10 \mathrm{MOI}$ of Adv-NOS3 or Adv-GFP and treated with nothing or NO donors (S-Nitrosoglutathione monoethyl ester [GSNO], $100 \mu \mathrm{M}$ or DETA NONOate [NOC-18], 100 

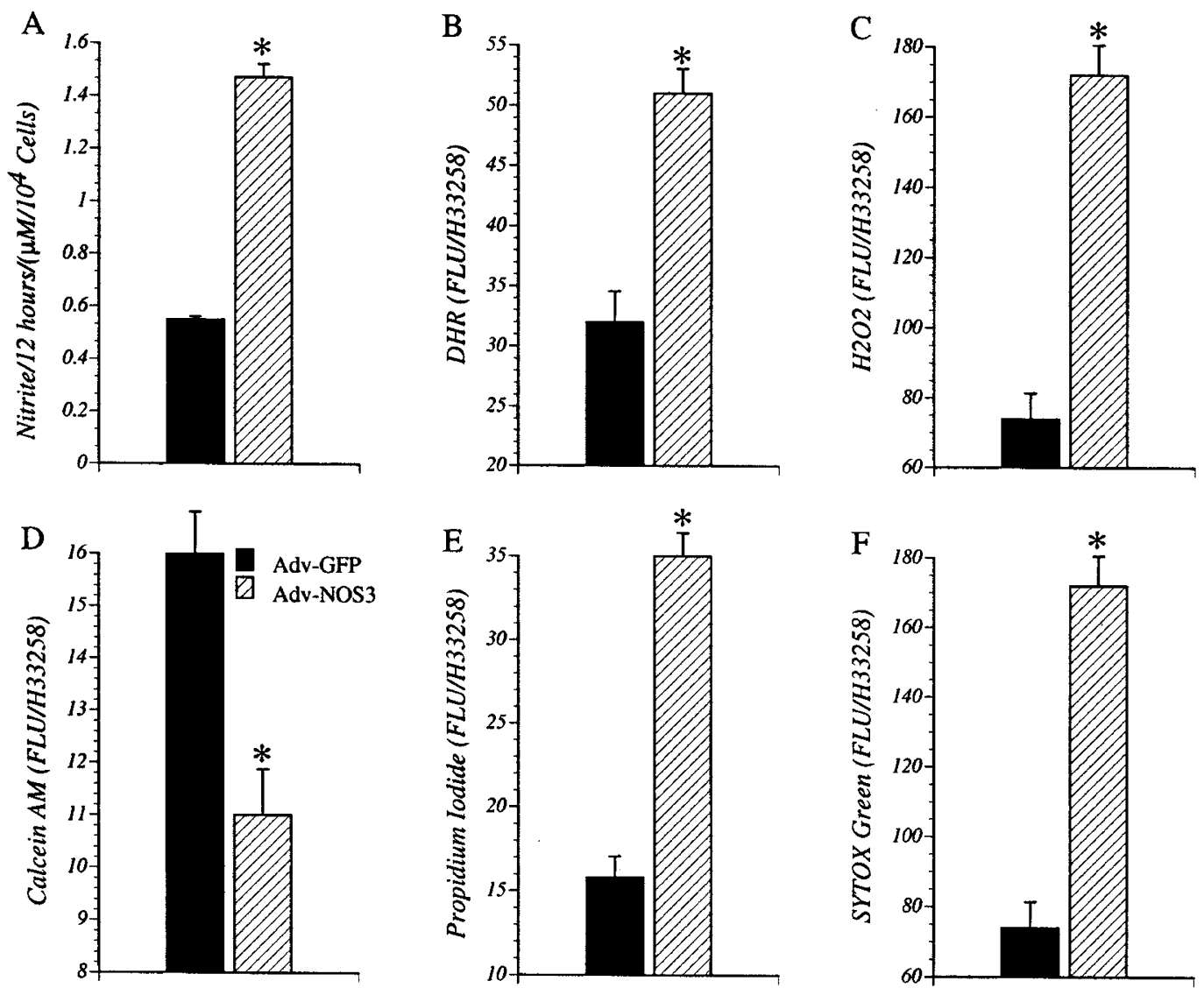

Figure 6.

Measurement of nitrite (A), free radical (B), and $\mathrm{H}_{2} \mathrm{O}_{2}$ (C) generation; cell membrane integrity (D); membrane permeability (E); and cytotoxicity related to increased membrane permeability (F). Cells grown in 96-well cultures and infected with $50 \mathrm{MOI}$ of Adv-NOS3 or Adv-GFP were analyzed for nitrite levels using Griess reagents, and oxidative stress as a result of free radical or $\mathrm{H}_{2} \mathrm{O}_{2}$ production was measured using the dihydrorosamine-6G (DHR; B) or Amplex Red hydrogen peroxide (C) assay. The nitrite levels were normalized to cell density. For assessing membrane integrity/permeability, live cells were labeled with Calcein AM, propidium iodide, or SYTOX Green, and fluorescence intensity was measured in a Fluorocount plate reader. Subsequently, the cells were fixed and stained with $\mathrm{H} 33258$ to assess cell density using the Fluorocount. The DHR, Amplex Red, Calcein AM, propidium iodide, and SYTOX Green fluorescence values were normalized to H33258 fluorescence measured in the same cultures after fixation. The graphed values depict the mean \pm SD of results. Between-group comparisons were made using Student $t$ tests ( ${ }^{\star} p<0.001$ ).

$\mu \mathrm{M})$, oxidants $\left(\mathrm{H}_{2} \mathrm{O}_{2}, 8.8 \mu \mathrm{M}\right.$, or diethyldithiocarbamate [DDC], $5 \mu \mathrm{M})$, an NOS inhibitor ( $\mathrm{N}^{\mathrm{G}}$-Nitro-L-arginine methyl ester [L-NAME], $100 \mu \mathrm{M})$, an antioxidant (Nacetyl-L-cysteine [NAC], $20 \mathrm{~mm}$ ), or an inhibitor of $\mathrm{Mt}$ permeability transition (cyclosporin A [CSA], $2 \mu \mathrm{M}$ ). Previous reports demonstrated that NO can promote apoptosis by inducing Mt permeability transition (Balakirev et al, 1997) and that NO-dependent apoptosis can be blocked with Mt permeability transition inhibitors such as CSA (Bosca and Hortelano, 1999). With the exception of the DDC treatment, which resulted in a $\sim 35 \%$ cell loss, viability in the Adv-GFPinfected cultures was relatively unaffected by the various chemical exposures (Fig. 8). In contrast, in the Adv-NOS3-infected cultures, treatment with DDC or $\mathrm{H}_{2} \mathrm{O}_{2}$ resulted in substantial reductions in viability, whereas treatment with L-NAME, NAC, or CSA resulted in significant increases in viability, and $\mathrm{NO}$ donor treatment had no significant effect on cell viability (Fig. 8).

To determine whether Mt function in the AdvNOS3-infected cells was similarly affected by the various treatments, NADH-TR activity was measured in cultures that were infected with Adv-GFP or Adv-
NOS3 and treated with nothing, L-NAME $(100 \mu \mathrm{M})$, $\mathrm{H}_{2} \mathrm{O}_{2}(8.8 \mu \mathrm{m})$, NAC (20 mm), CSA (2 $\left.\mu \mathrm{m}\right)$, GSNO (100 $\mu \mathrm{M})$, or NOC-18 (100 $\mu \mathrm{M})$. In the Adv-GFP-infected cultures, only the $\mathrm{H}_{2} \mathrm{O}_{2}$ treatment resulted in a significant decrease in the levels of NADH-TR activity (Fig. 9). In the Adv-NOS3-infected cultures, treatment with $\mathrm{H}_{2} \mathrm{O}_{2}$ resulted in substantial reductions in NADH-TR activity, whereas treatment with L-NAME, NAC, or CSA resulted in significant increases in NADH-TR activity. Exposure to GSNO or NOC-18 had no significant effect on NADH-TR activity in either the AdvNOS3- or Adv-GFP-infected cultures.

\section{Discussion}

This study demonstrates that high levels of NOS3 expression cause neuronal cell death that is mediated by apoptosis. Apoptosis was associated with Gn DNA damage, nuclear pyknosis, nuclear karyorrhexis, and increased levels of the p53, CD95, p21/Waf1, and Bax proapoptosis gene products. In AD, because the apoptosis and increased proapoptosis gene expression are primarily distributed in brain regions and neuronal populations that exhibit aberrantly increased levels of 
A

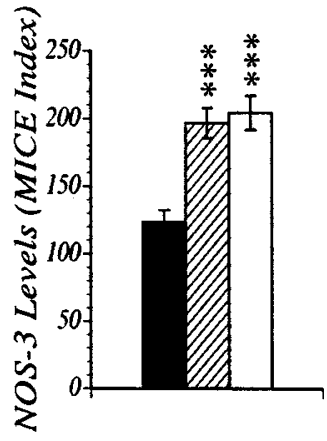

$\mathrm{E}$

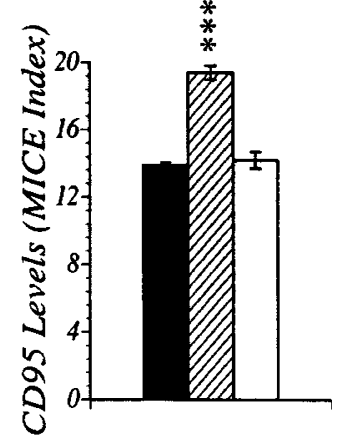

$\mathrm{B}$

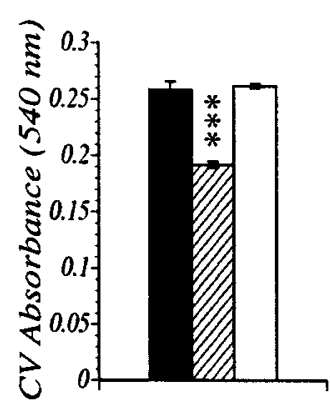

F

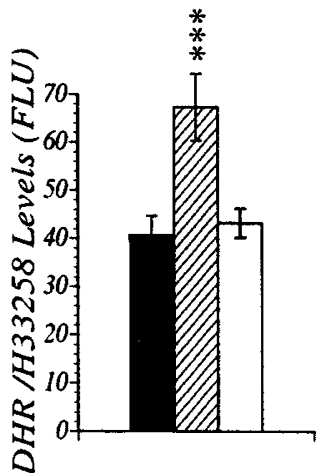

C

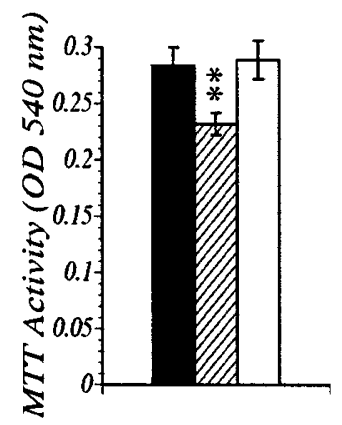

G

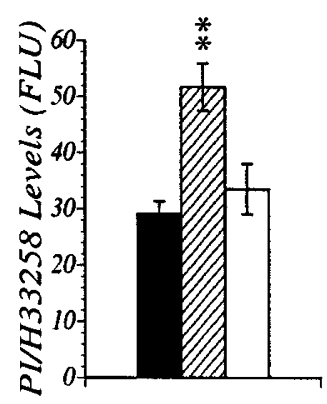

$\mathrm{D}$

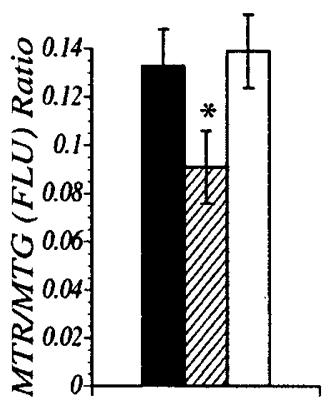

Figure 7.

Inhibitory effects of NOS3 on neuronal viability and Mt function do not occur when NOS3 is catalytically inactive. Neuronal cells were transfected with recombinant plasmid DNA encoding wild-type (wt) NOS3, NOS3 mutated in the catalytic domain (mut-NOS3), or nonrecombinant plasmid DNA (control). Studies were performed 48 hours after transfection using cells seeded into 96-well plates. Cells that were transfected with wt-NOS3, mut-NOS3, or vector were seeded into adjacent wells on the same plates to permit intergroup comparisons. A, NOS3 immunoreactivity was measured using the MICE. B, Viability was measured using the Crystal Violet assay. $C$ and D, Mt function was measured using the MTT assay $(C)$ and MitoTracker fluorescence (D). Data shown in D were generated by measuring MitoTracker Red (MTR) and MitoTracker Green (MTG) fluorescence, and calculating the MTR/MTG ratios for each culture well. E, CD95 immunoreactivity was measured using the MICE. F, Oxidative stress was measured by DHR fluorescence. G, Membrane permeability was assessed by measuring propidium iodide (PI) uptake. The levels of immunoreactivity, Mt function, DHR, and PI fluorescence indices were normalized with respect to cell density. For each experiment, data were collected from 16 replicate microcultures per group. The graphed values depict the mean \pm SD of results. Intergroup comparisons were made using ANOVA and the Fisher LSD post hoc test $\left({ }^{*} p<0.05 ;{ }^{* *} p<0.01 ;{ }^{* * *} p<0.001\right)$.

NOS3 expression (de la Monte and Bloch, 1997; Sohn et al, 1999), the findings herein suggest that the increased neuronal apoptosis associated with AD may be related to the aberrantly high levels of NOS3 expression.

Although apoptosis clearly occurs with AD neurodegeneration, the levels reported based on findings in postmortem tissue may overestimate the severity and rate of cell loss that occurs in vivo. One possibility is that degenerating neurons in $A D$ brains may more readily undergo apoptosis with terminal hypoxic insults. In this regard, a previous study demonstrated that cell loss in AD is mediated in part by enhanced susceptibility to apoptosis (Stadelmann et al, 1998). Correspondingly, results obtained herein showed that modestly elevated levels of NOS3 expression can render CNS neuronal cells more sensitive to oxidative injury. This effect was manifested by significantly reduced viability in Adv-NOS3-infected compared with Adv-GFP-infected cells that had been exposed to low levels of DDC or $\mathrm{H}_{2} \mathrm{O}_{2}$ as inducers of oxidative stress. In addition, the impaired viability may have been mediated by increased cellular levels of proapoptosis gene products, ie p53, Bax, and CD95. It is noteworthy that $A D$ neurodegeneration is associated with increased immunoreactivity for p53, CD95, and pro-death Bcl-family proteins (de la Monte et al, 1998; de la Monte et al, 1997; Kitamura et al, 1998; MacGibbon et al, 1997; Nagy and Esiri, 1997; Su et al, 1997; Tortosa et al, 1998).

Neuronal loss in AD is partly mediated by impaired Mt function (Cassarino and Bennett, 1999; de la Monte et al, 2000d; Ham and Schipper, 2000; Picklo et al, 1999). The present work demonstrates that NOS3 overexpression could impair neuronal Mt function, as evidenced by the significantly reduced levels of MTT and NADH-TR activities and MitoTracker Red fluorescence. The finding that cells that were treated with CSA, an inhibitor of Mt permeability transition, exhibited reduced oxidant production, increased cell membrane integrity, and increased viability and Mt function, despite high levels of NOS3, suggests several major functional abnormalities produced by NOS3 overexpression may have been mediated by impaired Mt function. In AD as well as other neurodegenerative diseases, high levels of NOS3 expression may play a critical role in compromising neuronal Mt function, which could lead to increased oxidative stress, reduced membrane integrity, and reduced neuronal viability.

Neuronal cells that overexpressed NOS3 had increased intracellular levels of oxidants, as demon- 


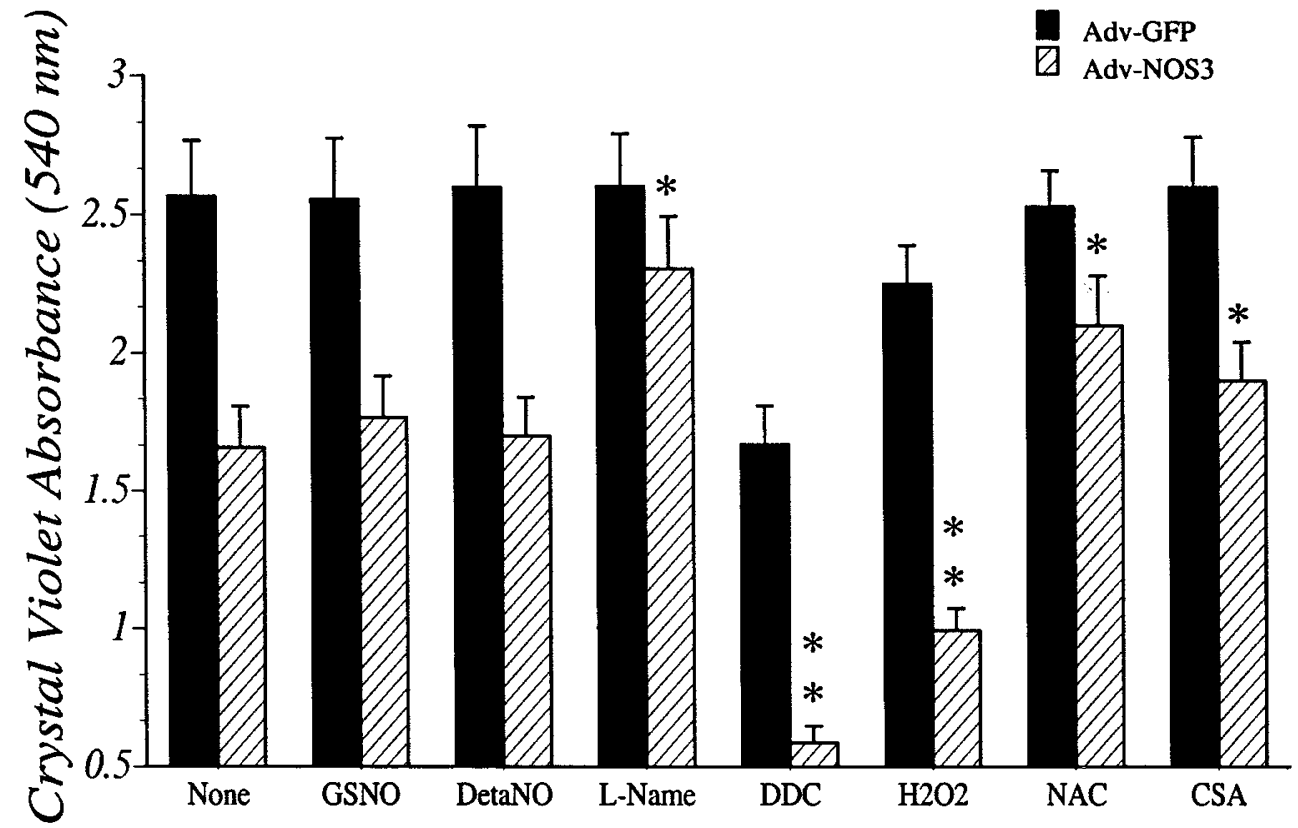

Figure 8.

Reduced viability after oxidative stress and partial rescue with an NOS inhibitor, antioxidant, or inhibitor of Mt permeability transition in Adv-NOS3-infected PNET2 cells. PNET2 neuronal cells cultured in 96-well plates were infected with $10 \mathrm{MOI}$ of Adv-NOS3 or Adv-GFP. Parallel cultures were simultaneously treated with S-Nitrosoglutathione monoethyl ester (GSNO; $100 \mu \mathrm{m}$ ) or DETA NONOate (NOC-18; $100 \mu \mathrm{M}$ ) as NO donors, NG-Nitro-L-arginine methyl ester (L-NAME; $200 \mu \mathrm{M})$ to inhibit NOS enzyme activity, diethyldicarbopyramate (DDC; $2100 \mu \mathrm{M})$ or $\mathrm{H}_{2} \mathrm{O}_{2}$ as oxidants, $\mathrm{N}$-acetyl-L-cysteine $(20 \mathrm{~mm})$ as an antioxidant, or cyclosporin A (CSA; 2 $\mu \mathrm{M})$ as an inhibitor of Mt permeability transition. Viability was measured 24 hours after infection using the Crystal violet assay. The graph depicts the mean ( \pm SD) of Crystal violet absorbances measured in eight replicate cultures. Asterisks indicate significant differences from untreated corresponding control (Adv-infected) cultures. Within-group comparisons were made using ANOVA with Fisher LSD post hoc tests for significance $\left({ }^{\star} p<0.01 ;{ }^{* \star} p<0.001\right)$.

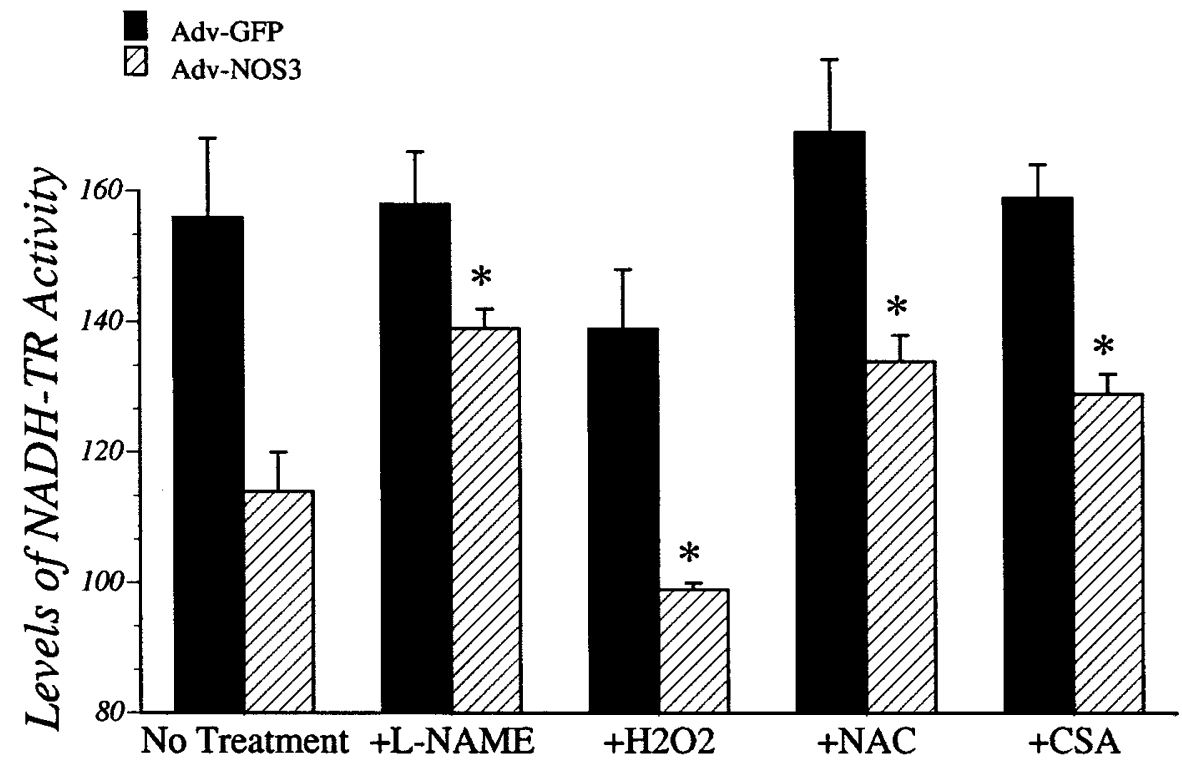

Figure 9.

Effects of L-NAME (NOS inhibitor), $\mathrm{H}_{2} \mathrm{O}_{2}$ (oxidant), NAC (antioxidant), and CSA (inhibitor of Mt permeability transition) on NADH-TR enzyme activity in cultures that were infected with $10 \mathrm{MOI}$ of Adv-NOS3 or Adv-GFP. NADH-TR enzyme activity was measured 24 hours after infection using enzyme histochemistry. Absorbances were measured in a Spectracount plate reader. The graphed data represent the mean ( $\pm \mathrm{SD}$ ) levels of NADH-TR activity. Within-group comparisons were made using ANOVA with Fisher LSD post hoc tests for significance ( ${ }^{*} p<0.01$ for differences between L-NAME-, $\mathrm{H}_{2} \mathrm{O}_{2}-$, NAC-, or CSA-treated and untreated Adv-NOS3-infected cultures).

strated with the DHR assay, which measures reactive oxygen species, and the Amplex Red fluorescence assay, which measures hydrogen peroxide generation. NO itself is a relatively weak oxidant, and in this regard, neuronal viability was unaffected by treatment with $\mathrm{NO}$ donors. However, when combined with $\mathrm{O}_{2}{ }^{-}$, the adverse effects of NO can be enhanced through the generation of peroxynitrite. $\mathrm{O}_{2}{ }^{-}$forms when free- 
radical scavengers are in short supply or when Mt function is impaired, as occurs with NOS3 overexpression or normal aging (Richter, 1992, 1995). The findings that in AD brains, high levels of NOS3 immunoreactivity were co-localize with nitrotyrosine, a marker of peroxynitrite (Sohn et al, 1999), and that PNET2 cells that were infected with Adv-NOS3 were rescued with an antioxidant ( $\mathrm{N}$-acetyl-L-cysteine) suggest that the increased apoptosis, apoptosis proneness, and Mt dysfunction associated with NOS3 overexpression are mediated by oxidative stress and free radical injury rather than the direct actions of NO.

NOS3 overexpression resulted in impaired neuronal membrane integrity manifested by reduced Calcein AM retention and increased labeling with propidium iodide and SYTOX Green fluorescent dyes, which are impermeant to normal cells but taken up by cells with damaged membranes. In the dose-effect studies, we demonstrated that neuronal membrane integrity was impaired with only modestly increased levels of NOS3 expression produced by infection with $10 \mathrm{MOI}$ of Adv-NOS3. Although low levels of NOS3 expression did not cause Mt dysfunction of loss of viability, they nonetheless rendered the neuronal cells more sensitive to oxidative stress. The mechanism may involve increased calcium influx, which could activate proapoptosis mechanisms. These results suggest that modestly increased levels of NOS3, as occur in many $A D$ brain neurons, may enhance sensitivity to oxidative stress by impairing the functional integrity of the cell membrane.

Increased cellular levels of reactive oxygen species result in opening of the Mt permeability transition pore, Delta psi(m) depolarization, irreversible cytochrome c release, and caspase activation (Bernardi, 1996). The proapoptosis effect of Bax is mediated by cytochrome c release through its actions at the $\mathrm{Mt}$ membrane (McGinnis et al, 1999). Previous studies demonstrated that high levels of $\mathrm{NO}$ and the attendant generation of reactive oxygen or nitrogen species cause apoptosis by inducing Mt permeability transition (Balakirev et al, 1997). NO-dependent apoptosis can be blocked with inhibitors of Mt permeability transition such as CSA or bongkrekic acid or with inhibitors of caspases (Bosca and Hortelano, 1999; Hortelano et al, 1997). However, because the CSA treatment only partially prevented the NOS3-mediated apoptosis and Mt dysfunction in the PNET2 cells, the neuronal cell death was likely mediated by the combined effects of impaired membrane integrity and Mt dysfunction precipitated by oxidative stress and activation of proapoptosis mechanisms. Moreover, the findings suggest that, given the importance of NO-mediated signaling in the CNS, safe and effective neuroprotection from the adverse effects of NOS3 overexpression in the context of AD neurodegeneration may be better effected by antioxidant therapy than by inhibiting NOS gene expression.

\section{Materials and Methods}

\section{In Vitro Model}

PNET2 human CNS-derived neuronal cells (The et al, 1993; Xu et al, 1995) were maintained in Dulbecco's modified Eagle's medium supplemented with $4 \mathrm{~mm}$ glutamine, $0.9 \%$ glucose, $1 \times$ nonessential amino acid solution (Sigma), and 10\% FCS. Subconfluent cultures seeded into $60-\mathrm{mm}$ dishes $\left(2 \times 10^{5}\right.$ cells/dish) or 96-well plates $\left(2 \times 10^{4}\right.$ cells/well $)$ were infected with recombinant Adv that expressed cDNA encoding NOS3 or GFP under the control of a CMV promoter (Janssens et al, 1996; Janssens et al, 1992). The Adv-NOS3 or Adv-GFP was added directly to the medium in the minimum volume required to cover the cells $(1.5 \mathrm{ml}$ for $60-\mathrm{mm}$ dishes, $50 \mu \mathrm{l}$ for 96-well plates). After 12 hours, fresh medium was added (3.5 $\mathrm{ml}$ for $60-\mathrm{mm}$ dishes, $150 \mu \mathrm{l}$ for 96 -well plates) to achieve standard culture conditions. The cells were studied $0,24,48$, or 72 hours after infection. Plaquepurified recombinant Adv was used throughout.

\section{Analysis of Apoptosis}

For detecting apoptosis, the cells were evaluated for Gn DNA nicking and fragmentation using a quantitative solution-based $\left[\alpha^{-32} \mathrm{P}\right] \mathrm{dCTP}$ end-labeling assay (Moyse and Michel, 1997). In addition, nuclear pyknosis and karyorrhexis were detected by Hoechst H33258 staining and fluorescence microscopy. Gn DNA was isolated as described previously (de la Monte et al, 2000b; de la Monte et al, 2000d). The degree of DNA fragmentation or nicking was assessed by measuring the levels of $\left[\alpha{ }^{-32} \mathrm{P}\right] \mathrm{dCTP}$ incorporated into high molecular weight DNA in reactions devoid of oligonucleotide primers (de la Monte et al, 2000b; de la Monte et al, 2000d; Moyse and Michel, 1997). Briefly, paired, duplicate 100-ng samples of Gn DNA were incubated for 15 minutes at $22^{\circ} \mathrm{C}$ in $20-\mu$ reactions containing $1 \times$ Klenow buffer, $1 \mathrm{U}$ of Klenow, and $0.2 \mu \mathrm{Ci}$ of $\left[\alpha^{-}{ }^{32} \mathrm{P}\right] \mathrm{dCTP}$. Labeled DNA was isolated using Wizard DNA Clean-up resin (Promega, Madison, Wisconsin), and $\left[\alpha^{-}{ }^{32} \mathrm{P}\right] \mathrm{dCTP}$ incorporation was measured in a scintillation counter. In addition, DNA laddering was detected by fractionating $10-\mu \mathrm{g}$ samples of Gn DNA in $2 \%$ agarose gels, staining the DNA with ethidium bromide, and photographing the gels under ultraviolet light.

Hoechst's H33258 staining was used for in situ detection of nuclear karyorrhexis and pyknosis associated with apoptosis. The cells were fixed with Histochoice solution (Amesco, Solon, Ohio) and permeabilized with $0.05 \%$ saponin in PBS. Replicate cultures were stained for 5 minutes at room temperature with $1 \mu \mathrm{g} / \mathrm{ml}$ Hoechst H33258 in PBS. After the labeled cells were rinsed in PBS, they were preserved under coverglass with Vectashield (Vector Laboratories, Burlingame, California) and examined by fluorescence microscopy. 


\section{Analysis of Mt Function}

Mt function was assessed using the MTT (Hansen et al, 1989) and NADH-TR (Dubowitz and Brooke, 1974) assays. Both assays were performed with cells seeded into 96-well plates at a density of $2 \times 10^{4}$ cells/well. The absorbances were measured in a Spectracount microplate reader (Packard, Meriden, Connecticut).

Mt mass and function were evaluated using MitoTracker mitochondria-specific cell permeable dyes (Molecular Probes). MitoTracker Green FM labels mitochondria irrespective of oxidative activity and therefore is used to assess Mt mass. MitoTracker Red (CM- $\left.\mathrm{H}_{2} \mathrm{Xros}\right)$ accumulates only in metabolically active mitochondria, and the reduced dihydrotetramethyl rosamine is rendered fluorescent via oxidation within the mitochondria. Cells grown in 96-well plates were labeled with MitoTracker Red or MitoTracker Green FM according to the manufacturer's instructions. After the fluorescence light units were rinsed in Tris-buffered saline (TBS; $50 \mathrm{~mm}$ Tris [pH 7.5], 0.9\% NaCl), they were measured with a Fluorocount plate reader (Packard Instrument Company, Meriden, Connecticut). Subsequently, the cells were stained with $\mathrm{H} 33258$ to determine cell density using the Fluorocount plate reader. H33258 fluorescence intensity was found to increase linearly with cell number between $1 \times 10^{4}$ and $5 \times 10^{5}$ cells/well (data not shown). MitoTracker Red/H33258 and MitoTracker Green/ H33258 ratios were used as indices of Mt function and Mt mass, respectively.

\section{Protein Expression}

Protein expression was assessed by Western blot analysis using previously described methods (Ausubel et al, 2000; de la Monte et al, 2000a; de la Monte and Wands, 2001). In addition, the MICE (de la Monte et al, 1999) was used to quantify immunoreactivity in 96well microcultures. The MICE combines the advantages of the enzyme-linked immunosorbent assay with immunocytochemical staining to permit in situ quantification of protein expression with values normalized to cell density (de la Monte et al, 1999). Briefly, the cells were fixed overnight, permeabilized with $0.05 \%$ saponin in TBS, and then blocked with SuperblockTBS (Pierce, Rockford, Illinois). The cells were then incubated overnight at $4^{\circ} \mathrm{C}$ with primary antibody $(0.5-1 \mu \mathrm{g} / \mathrm{ml})$ diluted in TBS containing $0.05 \%$ Tween-20 and $0.5 \%$ BSA. Immunoreactivity was detected with horseradish peroxidase-conjugated antimouse or anti-rabbit lgG (Pierce) and the TMB soluble peroxidase substrate (Pierce), according to the manufacturer's protocol. Absorbances were measured in a Spectrocount plate reader (Packard Instrument Company). Between incubations, the cells were washed three times ( 2 minutes per wash) in TBS with gentle platform agitation. Cell density was subsequently determined by staining the cells with Coomassie blue dye and measuring the absorbances of the eluates in a Spectracount plate reader (de la Monte et al, 1999). The MICE indices were calculated from the ratios of absorbances measured for immunoreactivity and cell density. Coomassie blue absorbance increases linearly with cell density between $1 \times 10^{4}$ and $5 \times 10^{5}$ cells per well. Eight or 16 replicate culture wells were analyzed in each experiment. All experiments were repeated at least three times.

\section{Detection of Oxidative Injury and Impaired Membrane Integrity}

For determining whether NOS3 mediated cell death was due to oxidative injury, the cultures were incubated with $50 \mathrm{MOI}$ of recombinant Adv, and 24 hours later, the cells were analyzed to measure reactive oxygen species, cytotoxicity, impaired membrane integrity, and hydrogen peroxide production by dihydrorosamine-6G (DHR), SYTOX Green, propidium iodide, Calcein AM, and Amplex Red fluorescence, respectively. After labeling for 15 to 30 minutes at $37^{\circ} \mathrm{C}$ according to the manufacturer's protocol (Molecular Probes), the cells were rinsed in TBS and fluorescence emission was measured in a Fluorocount plate reader (Packard Instrument Company).

\section{NOS3 Mutagenesis Experiment}

Human NOS3 cDNA was ligated into a pSport vector in which gene expression was regulated by a CMV promoter. Mutagenic oligodeoxynucleotides were designed to generate NOS3 mutants deficient in the L-arginine binding region, which previous studies demonstrated to be sufficient to render the NOS3 catalytically inactive (Chen et al, 1998). The D369I mutant was generated by PCR using the QuikChange Site-Directed Mutagenesis Kit (Stratagene, La Jolla, California) with the following primers: forward, GAGGAACCTGTGTATACCTCACCGCTACAACATCC; reverse, GGATGTTGTAGCGGTGAGGTATACACAGGTTCCTC, according to the manufacturer's protocol but using 2.5 U Pfu Turbo DNA polymerase per $50-\mu$ l reaction. The PCR amplification was performed using an initial $95^{\circ} \mathrm{C} 10$-minute denaturation/hotstart enzyme activation step, followed by 18 cycles of $95^{\circ} \mathrm{C}$ for 50 seconds, $55^{\circ} \mathrm{C}$ for 50 seconds, $68^{\circ} \mathrm{C}$ for 16 minutes, and concluding with a 16-minute incubation at $68^{\circ} \mathrm{C}$. The mutated cDNAs were sequenced in both directions to verify the presence of the specific nucleotide substitutions. Cells were transfected with recombinant plasmid DNA encoding wt or mut NOS3. Parallel experiments were conducted using cells transfected with nonrecombinant plasmid DNA. Transfections were performed using Lipofectamine 2000 (InVitrogen, Carlsbad, California), which consistently produced gene transfer in 40 to $60 \%$ of the cells.

Experiments were performed with cells seeded into 96-well plates at a density of $10^{4}$ viable cells/well, and cells that were transfected with the different plasmids were seeded in adjacent wells on the same plates to enable intergroup comparisons. Studies were performed 48 hours after transfection to coincide with the period of peak-level gene expression. Viability was measured using the Crystal Violet assay. Mt function was measured using the MTT assay and MitoTracker Fluorescence labeling. Oxidative stress was measured 
by DHR fluorescence, and membrane permeability was assessed by measuring PI uptake. NOS3 and CD95 immunoreactivity were measured using the MICE. Data were collected from 16 replicate microcultures per group for each experiment.

\section{Source of Reagents}

Monoclonal antibodies to p53 and p21/Waf1 were obtained from Oncogene Research Products (Cambridge, Massachusetts), and monoclonal antibodies to NOS3 and CD95 were purchased from Transduction Laboratories (Lexington, Kentucky). Polyclonal antibodies to Bax were purchased from Santa Cruz Biotechnology (Santa Cruz, California). Calcein AM, SYTOX Green, DHR-6G, Amplex Red hydrogen peroxide assay kit, and propidium iodide were purchased from Molecular Probes. MAb to a structural Mt protein was used as a negative control and purchased from Chemicon (Temecula, California). GSNO, NOC-18, DDC, L-NAME, NAC, and CSA were purchased from Calbiochem-Novabiochem (La Jolla, California).

\section{Statistical Analysis}

Data depicted in the graphs represent the means \pm SD generated with results obtained from three to six experiments. Intergroup comparisons were made using Student $t$ tests or ANOVA with Fisher least significant difference post hoc tests. Statistical analysis was performed using the Number Cruncher Statistical System (Dr. Jerry L. Hintze, Kaysville, Utah).

\section{References}

Ausubel F, Brent R, Kingston R, Moore D, Seidman J, Smith $\mathrm{J}$, and Struhl K, editors (2000). Current protocols in molecular biology. New York: John Wiley \& Sons, Inc.

Balakirev M, Khramtsov VV, and Zimmer G (1997). Modulation of the mitochondrial permeability transition by nitric oxide. Eur J Biochem 246:710-718.

Bernardi P (1996). The permeability transition pore. Control points of a cyclosporin A-sensitive mitochondrial channel involved in cell death. Biochim Biophys Acta 1275:5-9.

Boje K and Arora P (1992). Microglial-produced nitric oxide and reactive nitrogen oxides mediate neuronal cell death. Brain Res 587:250-256.

Bosca L and Hortelano S (1999). Mechanisms of nitric oxide-dependent apoptosis: Involvement of mitochondrial mediators. Cell Signal 11:239-244.

Bredt D and Snyder S (1994). Transient nitric oxide synthase neurons in embryonic cerebral cortical plate, sensory ganglia, and olfactory epithelium. Neuron 13:301-313.

Cassarino DS and Bennett JP Jr (1999). An evaluation of the role of mitochondria in neurodegenerative diseases: Mitochondrial mutations and oxidative pathology, protective nuclear responses, and cell death in neurodegeneration. Brain Res Brain Res Rev 29:1-25.

Chen PF, Berka V, Tsai AL, and Wu KK (1998). Effects of Asp-369 and Arg-372 mutations on heme environment and function in human endothelial nitric-oxide synthase. J Biol Chem 273:34164-34170.
Cotman CW and Su JH (1996). Mechanisms of neuronal death in Alzheimer's disease. Brain Pathol 6:493-506.

de la Monte S and Bloch K (1997). Aberrant expression of the constitutive endothelial nitric oxide synthase gene in Alzheimer's disease. Mol Chem Neuropathol 30:139-159.

de la Monte SM, Ganju N, Banerjee K, Brown NV, Luong T, and Wands JR (2000a). Partial rescue of ethanol-induced neuronal apoptosis by growth factor activation of phosphoinositol-3-kinase. Alcohol Clin Exp Res 24:716-726.

de la Monte SM, Ganju N, Feroz N, Luong T, Bannerjee K, Cannon J, and Wands JR (2000b). Oxygen free radical injury is sufficient to cause some Alzheimer-type molecular abnormalities in human CNS neuronal cells. J Alzheimers Dis 2:261-281.

de la Monte SM, Ganju N, and Wands JR (1999). Microtiter immunocytochemical ELISA assay. Biotechniques 26:10731076, 1078.

de la Monte SM, Lu BX, Sohn YK, Etienne D, Kraft J, Ganju $\mathrm{N}$, and Wands JR (2000c). Aberrant expression of nitric oxide synthase III in Alzheimer's disease: Relevance to cerebral vasculopathy and neurodegeneration. Neurobiol Aging 21: 309-319.

de la Monte SM, Luong T, Neely TR, Robinson D, and Wands JR (2000d). Mitochondrial DNA damage as a mechanism of cell loss in Alzheimer's Disease. Lab Invest 80:1323-1335.

de la Monte SM, Sohn YK, Ganju N, and Wands JR (1998). P53- and CD95-associated apoptosis in neurodegenerative diseases. Lab Invest 78:401-411.

de la Monte SM, Sohn YK, and Wands JR (1997). Correlates of p53- and Fas (CD95)-mediated apoptosis in Alzheimer's disease. J Neurol Sci 152:73-83.

de la Monte SM and Wands JR (2001). Alzheimer-associated neuronal thread protein-induced apoptosis and impaired mitochondrial function in human central nervous system-derived neuronal cells. J Neuropathol Exp Neurol 60:195-207.

Dinerman JL, Dawson TM, Schell MJ, Snowman A, and Snyder SH (1994). Endothelial nitric oxide synthase localized to hippocampal pyramidal cells: Implications for synaptic plasticity. Proc Natl Acad Sci USA 91:4214-4218.

Dubowitz V and Brooke MH (1974). Muscle biopsy: A modern approach. Philadelphia: WB Saunders Company Ltd.

el-Deiry WS (1997). Role of oncogenes in resistance and killing by cancer therapeutic agents. Curr Opin Oncol 9:79-87.

Esiri M and Morris JE (1997). The neuropathology of dementia. Cambridge, United Kingdom: Cambridge University Press.

Ghafourifar P and Richter C (1997). Nitric oxide synthase activity in mitochondria. FEBS Lett 418:291-296.

Ghafourifar P, Schenk U, Klein SD, and Richter C (1999). Mitochondrial nitric-oxide synthase stimulation causes cytochrome c release from isolated mitochondria. Evidence for intramitochondrial peroxynitrite formation. J Biol Chem 274: 31185-31188.

Giulivi C, Poderoso JJ, and Boveris A (1998). Production of nitric oxide by mitochondria. J Biol Chem 273:11038-11043.

Ham D and Schipper HM (2000). Heme oxygenase-1 induction and mitochondrial iron sequestration in astroglia exposed to amyloid peptides. Cell Mol Biol (Noisy-le-grand) 46:587-596.

Hansen MB, Nielsen SE, and Berg K (1989). Re-examination and further development of a precise and rapid dye method for 
measuring cell growth/cell kill. J Immunol Methods 119:203210.

Hess D, Patterson S, Smith D, and Skene J (1994). Neuronal growth cone collapse and inhibition of protein fatty acylation by nitric oxide. Nature 366:562-565.

Hortelano S, Dallaporta B, Zamzami N, Hirsch T, Susin SA, Marzo I, Bosca L, and Kroemer G (1997). Nitric oxide induces apoptosis via triggering mitochondrial permeability transition. FEBS Lett 410:373-377.

Janssens SP, Bloch KD, Nong Z, Gerard RD, Zoldhelyl P, and Collen D (1996). Adenoviral-mediated transfer of the human endothelial nitric oxide synthase gene reduces acute hypoxic pulmonary vasoconstriction in rats. J Clin Invest 98:317-324.

Janssens SP, Shimouchi A, Quertermous T, Bloch DB, and Bloch KD (1992). Cloning and expression of a cDNA encoding human endothelium-derived relaxing factor/nitric oxide synthase. J Biol Chem 267:14519-14522.

Kitamura Y, Shimohama S, Kamoshima W, Ota T, Matsuoka Y, Nomura Y, Smith MA, Perry G, Whitehouse PJ, and Taniguchi T (1998). Alteration of proteins regulating apoptosis, Bcl-2, Bcl-x, Bax, Bak, Bad, $\mathrm{ICH}-1$ and $\mathrm{CPP} 32$, in Alzheimer's disease. Brain Res 780:260-269.

Klatt P, Heinzel B, John M, Kastner M, Bohme E, and Mayer B (1992). Ca2 +/calmodulin-dependent cytochrome c reductase activity of brain nitric oxide synthase. J Biol Chem 267:11374-11378.

Klatt P, Schmidt K, Uray G, and Mayer B (1993). Multiple catalytic functions of brain nitric oxide synthase. Biochemical characterization, cofactor requirement, and the role of Nwhydroxy-L-arginine as an intermediate. J Biol Chem 268: 14781-14787.

Koch K, Lambrecht H, Haberecht M, Redburn D, and Schmidt $H$ (1994). Functional coupling of a Ca2+/calmodulin dependent nitric oxide synthase and a soluble guanylyl cyclase in vertebrate photoreceptor cells. EMBO J 13:3312-3320.

Koprowski H, Zheng Y, Heber-Katz E, Fraser N, Rorke L, Fu A, Hanlon C, and Dietzxchold B (1993). In vivo expression of inducible nitric oxide synthase in experimentally induced neurologic diseases. Proc Natl Acad Sci USA 90:3024-3027.

Lincoln J, Hoyle CHV, and Burnstock G (1997). Nitric oxide in health and disease, 1st ed. Cambridge: Cambridge University Press.

MacGibbon GA, Lawlor PA, Sirimanne ES, Walton MR, Connor B, Young D, Williams C, Gluckman P, Faull RL, Hughes P, and Dragunow M (1997). Bax expression in mammalian neurons undergoing apoptosis, and in Alzheimer's disease hippocampus. Brain Res 750:223-234.

McGinnis KM, Gnegy ME, and Wang KK (1999). Endogenous bax translocation in SH-SY5Y human neuroblastoma cells and cerebellar granule neurons undergoing apoptosis. J Neurochem 72:1899-1906.

Merrill J, Ignarro L, Sherman M, Melinek J, and Lane T (1993). Microglial cell cytotoxicity of oligodendrocytes is mediated through nitric oxide. J Immunol 151:2132-2141.

Mesenge C, Verrecchia C, Allix M, Boulu R, and Plotkine M (1996). Reduction of the neurological deficit in mice with traumatic brain injury by nitric oxide synthase inhibitors. J Neurotrauma 13:11-16.

Moyse E and Michel D (1997). Analysis of apoptosis-associated DNA fragmentation in vivo during neurodegeneration of the peripheral olfactory system in adult mammals. In: Poirier J, editor. Apoptosis techniques and protocols. Neuromethods, vol 29. Totowa, New Jersey: Humana Press, 133-159.

Nagy ZS and Esiri MM (1997). Apoptosis-related protein expression in the hippocampus in Alzheimer's disease. Neurobiol Aging 18:565-571.

Nishikawa T, Kirsch J, Koehler R, Bredt D, Snyder S, and Traystmann R (1993). Effect of nitric oxide synthase inhibition on cerebral blood flow and injury volume during focal ischemia in cats. Stroke 24:1717-1724.

O’Dell TJ, Huang PL, Dawson TM, Dinerman JL, Snyder SH, Kandel ER, and Fishman MC (1994). Endothelial NOS and the blockade of LTP by NOS inhibitors in mice lacking neuronal NOS. Science 265:542-546.

Perry G and Nunomura A (1998). Apoptosis and Alzheimer's disease (Letter). Science 282:1268-1269.

Picklo MJ, Amarnath V, Mclntyre JO, Graham DG, and Montine TJ (1999). 4-Hydroxy-2(E)-nonenal inhibits CNS mitochondrial respiration at multiple sites. J Neurochem 72:1617-1624.

Richter C (1992). Reactive oxygen and DNA damage in mitochondria. Mutat Res 275:249-255.

Richter C (1995). Oxidative damage to mitochondrial DNA and its relationship to ageing. Int J Biochem Cell Biol 27:647-653.

Satou T, Cummings BJ, and Cotman CW (1995). Immunoreactivity for $\mathrm{Bcl}-2$ protein within neurons in the Alzheimer's disease brain increases with disease severity. Brain Res 697:35-43.

Schmidt H and Walter U (1994). NO at work. Cell 78:919-925.

Sohn YK, Ganju N, Bloch KD, Wands JR, and de la Monte SM (1999). Neuritic sprouting with aberrant expression of the nitric oxide synthase III gene in neurodegenerative diseases. J Neurol Sci 162:133-151.

Stadelmann C, Bruck W, Bancher C, Jellinger K, and Lassmann H (1998). Alzheimer disease: DNA fragmentation indicates increased neuronal vulnerability, but not apoptosis. J Neuropathol Exp Neurol 57:456-464.

Su JH, Anderson AJ, Cummings BJ, and Cotman CW (1994). Immunohistochemical evidence for apoptosis in Alzheimer's disease. Neuroreport 5:2529-2533.

Su JH, Deng G, and Cotman CW (1997). Bax protein expression is increased in Alzheimer's brain: Correlations with DNA damage, Bcl-2 expression, and brain pathology. J Neuropathol Exp Neurol 56:86-93.

The I, Murthy AE, Hannigan GE, Jacoby LB, Menon AG, Gusella JF, and Bernards A (1993). Neurofibromatosis type 1 gene mutations in neuroblastoma. Nat Genet 3:2633-2642.

Tortosa A, Lopez E, and Ferrer I (1998). Bcl-2 and Bax protein expression in Alzheimer's disease. Acta Neuropathol (Berl) 95:407-412.

Vodovotz Y, Lucia M, Flanders K, Chester L, Xie Q-W, Smith T, Weidner J, Mumford R, Webber R, Nathan C, Roberts AB, Lippa CF, and Sporn MB (1996). Inducible nitric oxide synthase in tangle-bearing neurons of patients with Alzheimer's disease. J Exp Med 184:1425-1433.

Xu YY, Bhavani K, Wands JR, and de la Monte SM (1995). Insulin-induced differentiation and modulation of neuronal thread protein expression in primitive neuroectodermal tumor cells is linked to phosphorylation of insulin receptor substrate-1. J Mol Neurosci 6:91-108. 